\title{
Quantum Culture: A New Reflection on Schein's Model through a Scientific View
}

\author{
Nopparat Phaopat \\ National Institute of Development Administration \\ Oranuch Pruetipibultham \\ National Institute of Development Administration
}

In the global and dynamic world, mergers and acquisitions (M\&A) trend increases, especially in the technology industry (Deloitte, 2016). The incompatible culture is the top issue in $M \& A$ as the organizational trap for failure (Schmidt, 2002). The cross-pollination approach is applied in this study for generating the new holistic view. We propose the quantum-culture model as a reflection of Schein's organizational culture model that displays two different views: (a) scientific views integration approach; and (b) sociological multiparadigms approach. This emerging model aims to help HROD professionals in seeing and bridging the cultural gaps among subcultures within the main organizational culture.

\section{INTRODUCTION}

The global economic changes in the present world have generated a new business environment and new rules of the game for running an organization. These refined rules are needed for organizations to thrive and survive. HR researchers have reported that organizational leaders have identified the humancapital trend as the biggest challenge for building future organizations, especially issues regarding organizational culture (Deloitte, 2016, 2017). Economic competition will increase because of the industry 4.0 concept, where intelligent technologies and cyber-physical production systems will be the industrial highlights (MacDougall, 2014; United Nations, 2016).

Sociological changes, on the other hand, are helpful for understanding the rapid changes and instability in the current world. May and May (2014) introduced VUCA concept in order to describe four dimensions of change: (a) volatility - the speed of change; (b) uncertainty - the lack of predictability; (c) complexity - multiple choices and confusing chaos; and (d) ambiguity - the potential to misread a situation. Furthermore, the Internet plays a significant role in communication; borderless connections have emerged in society via social networking applications such as Facebook, Twitter, LinkedIn, etc. These applications also have created new behaviors on the part of people. Social network analysis (SNA) is an example of the new sociological approaches for analyzing structures and people relationships in order to address various organizational issues (Cheuk, 2007).

According to these changes, the merger and acquisition trend has increased as a managerial strategy to strengthen business competitiveness and economic certainty by acquiring higher existing sales volumes, new markets and products, new technologies, and other resources, especially in the technology 
industry (Cummings \& Worley, 2005; Deloitte 2016). Two success factors in mergers and acquisitions (M\&A), refers to both the singular and plural of this term) are the business and people dimensions, where people challenges are a vital cause of M\&A failure. The proposed top three notable M\&A difficulties are as follows: (a) incompatible cultures; (b) the inability to manage targets; and (c) the inability to implement change. The crucial interactions among subsidiaries during the integration involve strategic communication that should be established in order to increase organizational involvement (Schmidt 2002).

Scholars have studied the M\&A integration process based on social-identity theory and selfcategorization, as human factors, in order to understand people's perception of old and new organizational identities, especially regarding the "us and them" dynamic. The communication process in the organization is focused on as a cue for creating the positive perception of shared identities in the postmerger integration process. Even though organizational identification can be measured as relatively explicit, organizational culture is the tacit part (Hogg \&Terry, 2001; Kroon, 2017). Meanwhile, some researchers have examined the multiple shared identities that occur in cross-border M\&A situations where multiple group members have several functions and come from several countries. These multiple identities also reflect the higher identity complexity (Lupina-Wegner \& Dick, 2017). From a cultural perspective, corporate and national cultures are considered in the pre-merger (cultural due diligence $\mathrm{CDD}$ ) and post-merger integration (PMI) processes. Interestingly, the application of the stepfamily model as the condition of a contact is a cue for encouraging the success of corporate culture integration (Gaertner, Bachman, Dovidio, \& Banker, 2001). Previously, HRD professionals have applied systems theory in order to understand M\&A processes in organizations for the following aspects: (a) a big-picture view of consequences and relationships; (b) an integrated whole for better organizational alignment; (c) generating insights for better understanding of basic assumptions and perceptions; (d) developing a new discipline for achieving organizational learning; (e) establishing new models of systems thinking; and (f) avoiding the wrong focus and redundancy at all levels: individual, group, and organization.

These aspects can be considered in both states of open and closed systems (McLagan, 1989; Rieger, 1989). The mentioned studies have been partially conducted on M\&A process. Nevertheless, research studies have focused more on corporate culture achievement rather than on subculture study. Apparently, M\&A has not been completely handled sufficiently from a holistic view. Applying the systems theory contributes to a greater understanding of the complex M\&A phenomena and encourages new alternative disciplines in the processes of M\&A. The researchers' attempt is to explore this alternative way in order to better understand M\&A in today's fast-changing and dynamic environment.

\section{PURPOSE}

The purpose of this article is to provide a new and alternative way of looking at the organization through research studies from both social and scientific body of knowledges. Scholars have discussed the concept of "new knowledge," the notions related to many practices, in terms of the following: (a) expanding current knowledge into other fields; (b) crossing integrated fields of knowledge; (c) employing new tools, methods, and methodological approaches; and (e) using multiple or temporal lenses to observe phenomena across different levels of analysis (Ancona, Goodman, Lawrence, \& Tushman, 2001; Coelli \& Fleming, 2004; Eisner, 1997; Skitka \& Sargis, 2005). For example, Coelli and Fleming (2004) applied the idea of cross-pollination in order to achieve a "breakthrough outcome," such as the application of physics concepts to economic issues.

With these practices have been including expanding, the definition of "new" in this study is expanding, employing, integrating, investigating, and cross-pollinating multiple paradigms and fields of knowledge. Essentially, the cross-pollination approach is applied in order to generate a new view in this paper. In order to find a new way to understand the complex phenomena in the present organizational setting, we explore the quantum-culture model, which has emerged from two different world views: sciences (physics and chemistry) and sociology. 


\section{RESEARCH QUESTIONS}

The purpose of this paper is to answer the following research questions:

RQ1: What is quantum-culture like as a model?

RQ2: What are the characteristics of quantum-culture within the domain of M\&A?

\section{LITERATURE REVIEW}

Science is an empirical research for understanding the practical and theoretical domains; it has become a part of all social and scientific branches. In general, scientists and sociologists conduct research separately. Scientists generally, if not all cases, study natural phenomena of physical things (e.g., natural materials, molecules, the solar system, and the human body). Meanwhile sociologists study human behavioral aspects at many levels (e.g., individual, group, and the organization). Embracing the physical and human studies together helps in generating knowledge essential to the fast-changing world (Cook, 2008; Gallopin, Funtowicz, Connor, \& Ravetz, 2001). The integration of knowledge across boundaries and applying multiparadigm research allow scholars to obtain more comprehensive and new holistic views of the real world (Lynham, 2000; Swanson, 2001).

In order to better understand this scientific and social interchange, the related concepts in this article are depicted using the simple metaphor of water. This section is subdivided into: (a) the quantum realm by scientists; (b) the social realm by sociologists; and (c) the reflection on Schein's model from the scientists' view.

\section{Quantum Realm by Scientists}

\section{Physicist's Worldview}

Quantum theory is recognized as a breakthrough scientific theory and become the opposite idea that crash the classical physics of Newton. The scientific revolution in the 17th century, namely the Newtonian era, drastically changed people's view of Newton's three laws of motion in 1687: (a) an object moves continuously in a straight line if there is no interrupting force; (b) acceleration of an object correlates with the proportional force acting on it but is inversely proportion to its mass; and (c) every action has an equal and opposite reaction (Humphrey, Pancella, \& Barah, 2015; Wheatley, 2006). These laws enhanced knowledge regarding classical mechanics (machinery period), which helped to predict the fixed position of objects (even the moon) and separated humans from objects (machines).

"No problem can be solved from the same consciousness that created it" - Albert Einstein (Wheatley, 2006, p. 7).

Two hundred and eighteen years later, Albert Einstein proposed the quantum theory of light in 1905 (Nobel Prize received in 1921), which was at the time a vital breakthrough in physics. Apparently, the new theory of quantum by Einstein seemed to replace the old theory by Newton. Quantum theory focuses on the dimensions that are different from those of the Newtonian. Quantum theory contends that the field contains more than objects but integrates objects, information, and interaction all together. Therefore, focusing solely on the object does not provide sufficient evidence or information for thinking and understanding in the phenomena (Bohm, 1990; Humphrey et al., 2015; Wheatley, 2006; Zohar, 1990; Zohar \& Marshall, 1994).

Quantum definition, according to the law of physics, is the tiniest amount of physical quantity (Humphrey et al., 2015). Quantum concept is described as invisible existence of matter with particles that cannot be fixed by location and fully measured because the entire system relies on a great deal of interactive relationship rather than fixed forms (Bohm, 2005; Humphrey et al., 2015; McIntyry, 2012; Wheatley, 2006; Zohar, 1990). The quantum concept defies the size of an invisible matter by the scale of distances 100 billion times smaller than the diameter of the human hair (Bohm, 1952; Humphrey et al., 2015). Previously, several applications of quantum physics have been made in social science research, such as quantum self, quantum society, quantum and Newtonian thinking, and quantum skills (Fris \& Lazaridou, 2006; Zohar, 1990; Zohar \& Marshall, 1994). 
In addition, quantum physics embodies a new perception of the relations of things through the wave/particle dualism, whereby all phenomena are connected in all directions infinitely. The overall system as a whole can be highly significant view. The influence of one body on another via energy exchange without a physical appearance (nonlocality) is possible. The theory of hidden variables of Einstein elucidates the same pattern of pairs of correlated photons at the subatomic level. This nonlocality quantum-level correlation is new evidence of possibilities in the world of physics (Zohar, 1990). Furthermore, the experiment of Schrödinger's cat is a metaphor for "the relations of things". If it is the case, Zohar (1990) interestingly provided a good metaphor for the relations of things as below:

Unobserved quantum phenomena are radically different from observed ones - that is one major point of the story surrounding Schrödinger's cat. At the moment of observation, or measurement, previously unobserved electrons that were both waves and particles become wave or particles ... The metaphysical reality agent can't be the observer's measuring apparatus, or his eyes, ... all physical and thus all covered by Schrödinger's equation. Therefore, they conclude, it must be the observer himself who kill the cat - that is, the observer's disembodied, immaterial consciousness. (Zohar, 1990, pp. 41-43)

Obviously, this experiment demonstrates the nonlocality of possibilities that correlates to how the observer influences the outcomes. Therefore, the observer is inevitably included into the oneness of the system.

The following table provides comparison of key characteristics between the Newtonian and the quantum physics.

TABLE 1

\section{COMPARISON OF KEY CHARACTERISTICS BETWEEN NEWTONIAN AND QUANTUM THINKING (Bohm, 2005; McIntyre, 2012; Zohar, 1990)}

\begin{tabular}{|c|c|c|}
\hline $\begin{array}{c}\text { Key } \\
\text { characteristics }\end{array}$ & Newtonian & Quantum \\
\hline Being & $\begin{array}{l}\text { - Reality is perceived as physical thing } \\
\text { exists. } \\
\text { - Thing is fixed, determined, and fully } \\
\text { measured. } \\
\text { - How can anything ever happen? }\end{array}$ & $\begin{array}{l}\text { - Reality is perceived as nothing exists, but } \\
\text { energy. } \\
\text { - Nothing is fixed, determined, and fully } \\
\text { measured. } \\
\text { - How can anything ever be? }\end{array}$ \\
\hline Moving & $\begin{array}{l}\text { Locality, an object moves continuously } \\
\text { from one point to the other by a given } \\
\text { force and time. }\end{array}$ & $\begin{array}{l}\text { - Nonlocality, there are no actual objects but } \\
\text { possibilities fix itself simultaneously in every } \\
\text { direction at once. }\end{array}$ \\
\hline Relationship & $\begin{array}{l}\text { - Separation in the system, the variables } \\
\text { are measured by observer as outsider. } \\
\text { - Particle relies on its behavior. }\end{array}$ & $\begin{array}{l}\text { - Oneness in the system, the hidden variables are } \\
\text { not fully measured because the observer is a } \\
\text { part of it. } \\
\text { - Wave relies on particles' interactive behaviors. }\end{array}$ \\
\hline
\end{tabular}

Regarding this new notion of relations by intangible part in quantum theory, the hidden variables at subatomic as subculture level in M\&A process are still not explored according to the true oneness of the system. Meanwhile, previous studies have been based on the notion of action at a snapshot rather than a holistic view. Following Zohar (1990), we believe that there may be unobserved phenomena in social integration and interaction called M\&A, waiting to be observed and understood by studying more about the quantum concept.

Furthermore, applying a unified approach in quantum chemistry, Cook (2008) showed that both Newtonian and quantum co-exist in the system. It depends on how large the scale and which levels that we are looking for. For example of large-scale and visible level, Newton's laws provide the calculation of 
the internal motions of the solar system based on the number of bodies and their mass such as the moons move around the planet and the planet moves around the sun. Meanwhile, for example of small-scale and invisible level, quantum way calculates the distribution of energies of the electrons in the ethanol molecule based on the number of bodies, their mass and charges, and interaction among bodies. Thus, the whole system can be broken down into a series of interacting smaller sub-systems.

\section{Chemist's Worldview}

The basic question of chemists is what are the matter and molecules made of. The chemists put effort into understanding the deeper composition of substances in our world by the exciting experiments of the nature. This research focuses on three levels of matters, molecules, and atoms in terms of their internal engaging forces and how they adjust themselves when receiving various interruptions from external forces (e.g., shaking, heating, and chemical reactions).

"Truth is ever to be found in the simplicity, and not in the multiplicity and confusion of things" - Sir Isaac Newton (Mazzocchi, 2008, p. 10).

The metaphor of water, the most wide-spread matter on earth (Shiklomanov, 1998), is used for a simple explanation of three levels of substance composition in a scientific way. Chemists have indicated that chemical bonding shows how atoms are bonded together in molecules and how molecules stay together in different phases of matter. These three levels of natural relationships in substances are explained using the metaphor of water, shown in Figure 1: a) the physical level, to explore how molecules remain in phases of matter that are solid, liquid, and gas; b) the molecular level, to explore bonding in matter; and c) the atomic level, to explore atomic shape and space (Cook, 2008; McMahon, Khomtchouk, $\&$ Wahlestedt, 2017). Figure 1 below depicts quantum chemistry in water.

\section{FIGURE 1 THREE LEVELS OF RELATIONSHIPS OF SUBSTANCES IN NATURE}

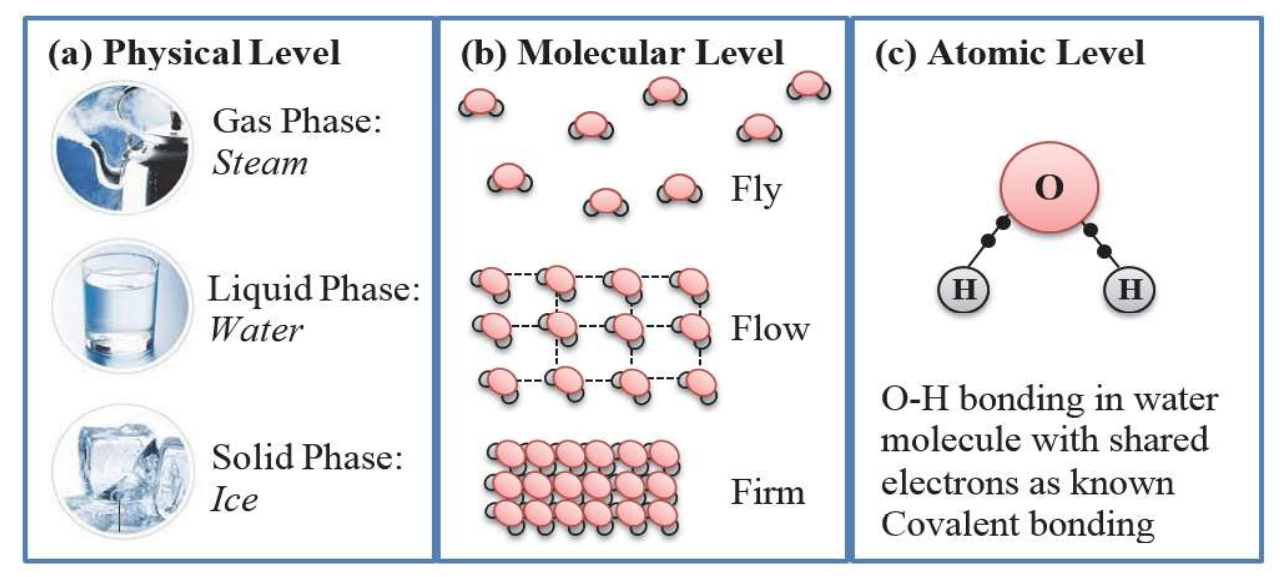

The general concepts in chemistry related to these three levels are explained as follows:

(a) Physical level: The three phases of water are solid (ice), liquid (water), and gas (steam). These phases change by varying the pressure or temperature during each phase (Horn, Swope, Pitera, Madura, Dick, Hura, \& Head-Gordon, 2004). The physical phases changing processes are theoretically reversible (solid $\leftrightarrow$ liquid $\leftrightarrow$ gas) (McMahon et al., 2017). However, the water in each phase still exists physically as water $\left(\mathrm{H}_{2} \mathrm{O}\right)$ matter, and does not change into different matter. The water molecules, in different phases, are dispersed away from each other or condensed into a cluster. When a phase changes into another, it needs to increase or reduce some amounts of heat energy, such as: (a) ice-to-liquid-to-steam is heat consumption; and (b) steam-to-liquid-to-ice is heat reduction (Granger, 2017; McMahon et al., 2017). 
(b) Molecular level: looking more deeply into a smaller scale for a single water molecule $\left(\mathrm{H}_{2} \mathrm{O}\right)$, it can be seen that it is bonded to surrounding molecules through hydrogen bonding with a specific energy, density, and temperature. Hydrogen bonding is an attachment form by the strong dipole force between positive end on H-atom and negative end on another atom, which is stronger than other dipole forces (McMahon et al., 2017). The length of the hydrogen bond in each phase of water is shortest in the solid phase, middle in the liquid phase, and longest in the gas phase. These different lengths impact the mobility of the water material from slowest in ice, middle in water, and to fastest in steam (Abascal \& Vega, 2005).

(c) Atomic level: A water molecule is made of two hydrogen atoms $(\mathrm{H})$ and one oxygen atom $(\mathrm{O})$. The H-O bonding is a covalent bond that is "a shared pair of electrons between two atoms" (McMahon et al., 2017, p. 1). The electrons of this bond, always only two, are able to move around in the overlapping space of the bonded two atoms, known as molecular orbital (localized atomic orbital). These molecular orbitals determine the shape or structure of the 3-D arrangement of a molecule, known as stereochemistry. The stereochemistry also determines the physical properties (e.g., color, mass, volume, shape, phases, melting and boiling points) and the chemical properties (e.g., acid, base, reaction) (Ma, 2016; McMahon, 2017). The electron movement creates mixed-wave and energy exchanges among these two atoms, but never gets in close to their nucleus. That means that these two atoms have a certain range of distance or space among them with a specific shape or structure, as shown in Figure 2 (Cook, 2008; Horn et al., 2004; McMahon et al., 2017).

FIGURE 2

A WATER MOLECULE COMPRISES PAIRED AND LONE-PAIRED ELECTRONS, POSITIVE AND NEGATIVE DIPOLES, AND THE RELEVANT STRUCTURAL SHAPE

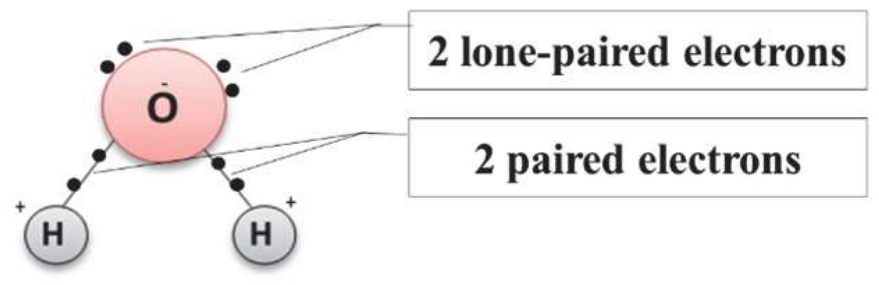

\section{Social Realm by Sociologists}

Systems Theory

According to the Aristotelian worldview, the whole is greater than the sum of its parts. Complex problems cannot be resolved by only one view. Thus, scientists began looking at the system approach to dynamic and complex matter, such as in a living organism, a galaxy, a social group, and an atom (Bertalanffy, 1972). Viewed on a micro scale every small unit (bit) is partial in an all, and the all also contains every bit (Gradous, 1989). Every bit and all interact with each other in a feedback loop shown in Figure 3 below. To understand a system, therefore, it depends on what scale we are looking at and how related things are in the systems.

FIGURE 3

MICRO VIEW OF SYSTEM THEORY, ADAPTED FROM BOOTHE, 1989

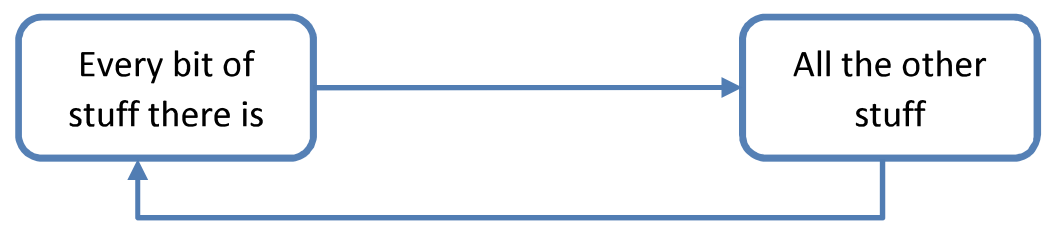


In social science, general systems theory suggests that there are subsystems inside the system. The subsystems are not only parts but their interrelations affect the system as well. The natural components and interaction forces among the subsystems impact the structures of subsystems and the main system, either in an open or closed state (Bertalanffy, 1972). HRD professionals perceive systems theory as a way to exchange information by asking and answering questions. Such that, the system and subsystems theory, considerably useful to the field of HRD (Boothe, 1989), can be magnified in the below discussion of organizational cultures and subcultures.

\section{Organizational Cultures and Subcultures}

Phaopat and Mak (2017) reviewed the models of organizational culture from 1976 to 2015 from 14 studies, they found that the researchers mainly focused on classification for typology and diagnosis for understanding the cultural characteristics. Interestingly, none of them examined the interaction and relationship between subcultures within the main culture. Hence, it is essential to shed light upon the underexplored areas of subculture within the main organizational culture.

According to Schein's organizational culture study, the explosion of new tools in information technology and media transmission accelerated several cross-cultural activities and created increasing need for researchers to explore cultural phenomena in the information age. Both national and ethnic cultures were examined through manifold occupational groups. Schein (2010) proposed four categories of culture: (a) macrocultures at the global level (e.g. nations and religions); (b) organizational cultures of institutions; (c) subcultures in groups within organizations; and (d) microcultures in the microsystem both within and outside organizations. Essentially, Schein described three levels of organization cultures: (a) artifacts such as technology, art, and visible and audible behaviors; (b) values such as testability in the physical environment and social consensus; and (c) basic assumptions, such as relationships with the environment, the nature of reality-time-space, and human nature.

The cultural assumptions have been influenced significantly through the technology transmission in the digital age. Organizations aim to maintain their cultural uniqueness and to adapt to the rapid changing environment, and thus the founder-generated culture may cease to exist in the new world. This rapidlychanging environment has been triggered tremendously by the increase in information technology (IT), media transmission, and all other technologies. These changes have generated many more opportunities for people to connect and to access new and unique cross-cultural phenomena, and this has impacted the complexity of the cultural studies (KPMG, 2013; Schein, 2010). The changing environment impact organization in a way a water molecule gets various interruptions from external forces (e.g., shaking, heating, and chemical reaction). In M\&A, several organizations are forced to change because of the external environment causing radical changes in the structures, visions, missions, policies, and artifacts at the outermost layer.

The metaphorical comparison between the levels of Schein's cultures versus the natural scientific relationships in water is shown in Figure 4. Further explanation is provided in the section "conceptualization of the quantum-culture model"

\section{FIGURE 4}

\section{COMPARISON OF SCHIEN'S CULTURAL LEVELS AND THE THREE LEVELS OF THE NATURAL SCIENTIFIC RELATIONSHIPS IN WATER}

\begin{tabular}{|l|l|l|}
\hline Artifacts: Visible and audible & & $\begin{array}{l}\text { Physical level: Matter of water with three } \\
\text { phases (ice, water, steam) }\end{array}$ \\
\hline $\begin{array}{l}\text { Values: Testable in the physical } \\
\text { environment, social consensus }\end{array}$ & & $\begin{array}{l}\text { Molecular level: Physical environment } \\
\text { impact on movement (Firm, Flow, Fly) }\end{array}$ \\
\hline $\begin{array}{l}\text { Basic Assumptions: Nature of reality, } \\
\text { time, space, and relationships }\end{array}$ & & $\begin{array}{l}\text { Atomic level: Natural bonding relationships } \\
\text { (covalent bond and atomic orbital) }\end{array}$ \\
\hline
\end{tabular}


According to the classical physics of Newton (object/particle focus) and the quantum theory (relation/wave focus), these two perspectives are related to the comparison in Figure 4. At the top, the artifacts and physical levels can be compared to the observable objects in the physical phase changes. In the middle, the values and molecular levels are testable or measurable, but the objects can be visible and invisible at the same time (e.g., the ice and water can be seen while the steam may be seen or not, depending on its density). Last, at the bottom, the basic assumptions and atomic levels share the similarity of unobserved phenomena but their existence is occupied by the relationships and energy without physical appearance (nonlocality).

\section{CONCEPTUALIZATION OF THE QUANTUM CULTURE MODEL}

This section contains the following: a) a review of mergers and acquisition as a chemical reaction; b) proposes a quantum-culture model to address the first research question: "what is the quantum-culture like as a model?" ; and c) answers the second research question: "what are the characteristics of quantumculture within the domain of M\&A?".

\section{Mergers and Acquisitions as a Chemical Reaction}

Substance interactions in daily life can be observed, such as (a) physical mixtures (e.g., mixture of sugar, salt, and powder); (b) solutions (e.g., water as solvent and sugar as the solute becomes syrup); and (c) reactions (e.g., iron reacts with moisture and oxygen in the air and becomes rust). According to the statements of the chemical concept, Abraham, Grzybowski, Renner, and Marek, (1992, p. 107) proposed:

1. Chemical-change concept - A chemical change is a transformation resulting in the formation of a new substance...2. Dissolution concept - A solution forms when two or more substances mix homogeneously...5. Phase-change concept - Heat energy is needed to change the phase of a materials.

The chemical concepts of chemical-change and dissolution are comparable with the integration types for M\&A. Integration philosophies for M\&A are proposed in four types: (a) limited integration maintaining separation; (b) dominant company - absorption subsidiary into main organization; (c) mutual best of both - integration of the best practices from two subsidiaries into new company; and (d) transformation to a new company - integration of the best practices from two subsidiaries with the external best practice into new one company. Figure 5 shows all four types of integration philosophies (Schmidt, 2002). 


\section{FIGURE 5}

\section{FOUR TYPES OF INTEGRATION PHILOSOPHIES, ADAPTED FROM SCHMIDT, 2002}

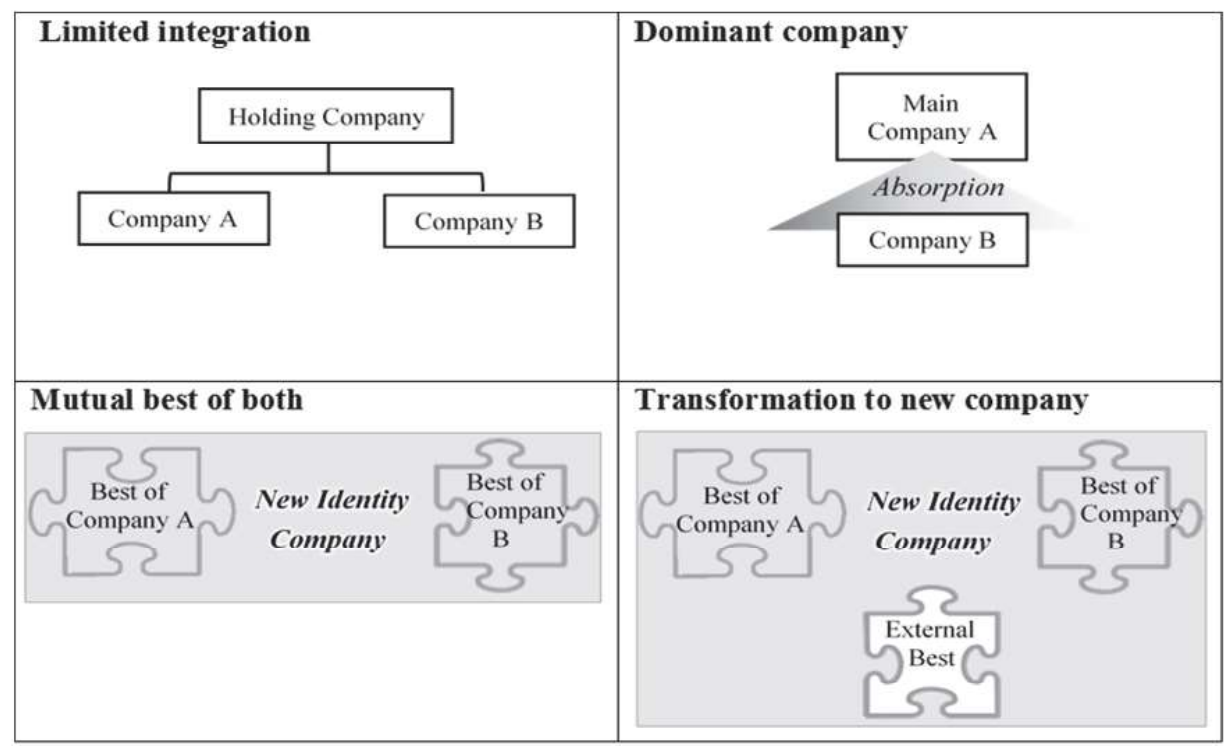

Limited integration is like the physical mixture of matter without a reaction. The dominant company is like the solution of a solvent (company A) and solute (company B). Meanwhile, the mutual best of both and the transformation to a new company are like chemicals reactions. Therefore, the analogy of "M\&A as a chemical reaction" is applicable to the two integration philosophies, the mutual best of both and the transformation to a new company.

Why should water be used as an M\&A metaphor? Water is a common and essential substance in life, and is made from the reaction between two hydrogen molecules (gas phase, $\mathrm{H}_{2}$ ) and one oxygen molecule (gas phase, $\mathrm{O}_{2}$ ) (Granger, 2017). According to Figure 6, when hydrogen gas has a reaction with oxygen gas, the water emerges as a new substance that differs from previous substances. This reflects how natural substances can be transformed and therefore used as a metaphorical transformation in the organization. When company A has merged with company B, a new company X can emerge. The characteristics of company $\mathrm{X}$ could become completely different from those of company A and B. Thus, an absolute transformation process emerges.

FIGURE 6

THE CHEMICAL EQUATION FOR WATER FORMULATION AS A METAPHOR FOR M\&A

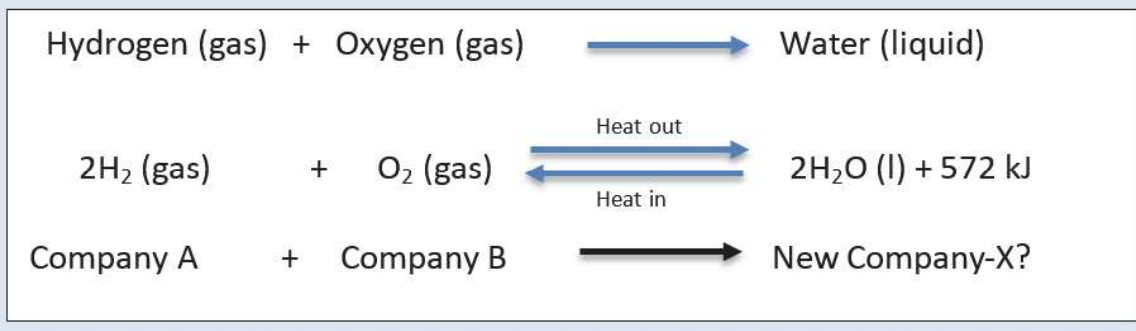

Surrounding Environment: Mass, Pressure, Temperature, and Time

The "heat in" in this equation means the temperature that impacts the environment. The "heat out" is exothermic - the surrounding atmosphere has a higher temperature. Meanwhile, the "heat in" is 
endothermic, where the surrounding atmosphere has a lower temperature (Granger, 2017; McMahon et al., 2017). The $572 \mathrm{~kJ}$ is the consumption energy to convert $\mathrm{H}_{2} \mathrm{O}(\mathrm{l})$ back to $\mathrm{H}_{2}(\mathrm{~g})$ and $\mathrm{O}_{2}(\mathrm{~g})$ substances. From a sociologist's view, this energy reflected that the combination process need to release something from organization such as downsizing impact. From HRDO's point of view, this effort energy can be reflected through the merging process in which certain "release" need to be done, such as downsizing process and outcome. Meanwhile, the separation process needs to "add" something in to remain organizational balance, such as the surveillance package for the individual units.

Nevertheless, it can be very difficult for scientists to make water in laboratories, even though the WWAP (World Water Assessment Programme by United Nations) $(2006,2018)$ reported that $20 \%$ of the people in the world still cannot reach out to clean water; and there has been an increasing rate about $1 \%$ per year for global water demand from 2018 and will continue over the next 20 years. The reason is that simply mixing the two gases at room temperature may not create water but a big boom; an example can be seen in the Hindenburg disaster of airship LZ 129 in 1937. Because oxygen supports combustion, it is essential to control ratio by putting the right amount of oxygen, hydrogen, pressure, and temperature to prevent the deadly explosion (Ashish, 2015; Helmenstine, 2018). Based on thermodynamic properties, the calculation method for the ignition process and reaction mechanism in hydrogen-oxygen mixtures show the possibility of 37 elementary reactions (such as $\mathrm{H}_{2}, \mathrm{O}_{2}, \mathrm{OH}, \mathrm{H}, \mathrm{O}, \mathrm{HO}_{2}, \mathrm{H}_{2} \mathrm{O}$, and $\mathrm{H}_{2} \mathrm{O}_{2}$ ) related to mass, pressure, energy, temperature, and time. These 37 possible reactions are forwarded and reserved mechanisms of hydrogen-oxygen-water (Maas \& Warnatz, 1988).

As such, making a chemical reaction to render a new substance requires several factors involving direct initial matter, related energy, pressure, time, etc. Yet, it is not certain that the reaction will generate the expected or complete product $\left(\mathrm{H}_{2} \mathrm{O}\right)$. This chemical reaction of water can metaphorically reflect an idea that the new form of the organization after the integration process may not completely be the same as the initial entities or may become a total failure. Beyond the expected results, the unexpected side effects (e.g., bind products/defection, high temperature/frustration, and strong pressure/group conflicts) also occur during the reaction processes. Therefore, the handling of the integration process with a true holistic view helps the hidden variables to emerge. Acknowledgement on the identity of initial matter, and the expected and unexpected results, bring awareness and acceptance to the acquirer company that organizational transformation may not render the completion as expected.

What is a guideline for working on the integration process? At the atomic level, the $\mathrm{H}$-atom and Oatom in the water molecule $\left(\mathrm{H}_{2} \mathrm{O}\right)$ are bridged by "the covalent bond" with electron sharing. Without the electron separation from the initial matter (gas molecule-to-atom) and building electron sharing, the new matter (water) cannot exist (McMahon et al., 2017). Comparably, the freeing from old identities (e.g. letting go of the previous workplace and working styles, familiarizing to a new workplace, adjusting to a newly assigned job) and the new resource sharing (e.g. sharing the working space, manpower, patents, and facilities) are the basic needs as the success factors in M\&A. 


\section{FIGURE 7 \\ A PROPOSED CONCEPTUAL MODEL - THE QUANTUM-CULTURE MODEL COMPRISES THREE DIMENSIONS OF CAUSAL RELATIONSHIPS IN ORGANIZATION}

\begin{tabular}{|c|c|c|}
\hline Atom-to-Molecule-to- & Iatter as Subculture-to-Main C & ture-to-Organization: \\
\hline $\begin{array}{l}\text { Energy = Resource } \\
\text { - Freeing } \\
\text { - Sharing } \\
\text { - Cohering } \\
\text { - Exchanging }\end{array}$ & $\begin{array}{c}\text { Bonding Distance }=\text { Contract } \\
\text { - Mutual space } \\
\text { - Privacy space }\end{array}$ & $\begin{array}{l}\text { Orbital Shape }=\text { Structure } \\
\text { - Observing \& Measuring } \\
\text { level } \\
\text { - Execution level }\end{array}$ \\
\hline \multicolumn{3}{|c|}{ Appropriate Surrounding Environment } \\
\hline
\end{tabular}

\section{Proposed Quantum-Culture Model}

Essentially, a conceptual framework, known as quantum culture arose in the finding of this study. We propose an interaction-based framework, quantum culture, to better understand the changing nature of organizations in M\&A era. Quantum culture comprises three dimensions of causal relationships: (a) energy as resource; (b) bonding distance as contract; and (c) orbital shape as structure, as shown in Figure 7.

\section{Dimension 1: Energy as Resource}

The freed atom $(\mathrm{H}, \mathrm{O})$ from the previous molecule $\left(\mathrm{H}_{2}, \mathrm{O}_{2}\right)$ is the first step before changing into a new identity. The paired electrons on a covalent bond represent sharing behavior from each atom for maintaining a strong engagement. Meanwhile, the hydrogen bond, between the $\mathrm{H}_{2} \mathrm{O}$ molecules in ice, water, and steam, represents cohering behavior through the attraction of opposite dipoles (positive-pole on H-atom and negative-pole on $\mathrm{O}$-atom). The exchanging behavior in the $\mathrm{H}_{2} \mathrm{O}$ molecule occurs in the overlapping orbital space, in which an electron of the pair can move around, bonded two atoms for energy exchanging. Thus, we propose that the key social behaviors at this initial level be freed from the old identity, sharing resources, cohering with complementary resources, and exchanging a sufficient amount of resources. These behaviors are basic needs for starting relationships among subcultures.

\section{Dimension 2: Bonding Distance as Contract}

A covalent bond allows only two electrons to be in a specific overlapping space (bonded area). However, there is a distance gap that does not allow two nuclei from two atoms to move in close. These phenomena represent the conditions of bonding agreement as contract. Therefore, we propose that the important behaviors at this middle level be acknowledgement and paying respect to mutual space (bonding distance) and privacy space (nucleus distance). These two behaviors strongly support the maintenance of healthy relationships among the organizational members.

\section{Dimension 3: Orbital Shape as Structure}

Chemical bonding and stereochemistry have a causal relationship that determines the properties of matter (physical and chemical aspects). Samantha Ma stated in the physical and chemical properties of matter article that "Physical properties can be observed or measured without changing the composition of matter... Chemical properties of matter describes its 'potential' to undergo some chemical change or reaction by virtue of its composition" (Ma, 2016, retrieved from https://chem.libretexts.org/ Core/Inorganic_Chemistry/Chemical_Reactions/Properties_of_Matter on September 15, 2017). This statement reflects the different levels of matter as visible (physical) and invisible (chemical). When 
compared metaphorically to Schien's cultural levels, we believe that physical property is equivalent to the artifact level, and chemical property is equivalent to values and basic assumption levels.

Furthermore, the level-changing is influenced by the external energy (e.g., heat, waves, vibrations), which leads to different outcomes such as new substances or the same substance in new shapes. Example phenomena are: (a) the phase changes in visible matter; (b) the molecule movement speed changes in different phases such as solid firm-liquid flow-steam fly; and (c) the atomic reaction changes into new matter as separation or combination. Different changes require different amounts of energy and different way the energy is used in the process.

The third level reflects the ability of the organization to cope with external changes or disturbances. Before the organizations adjust themselves according to the amount and speed of change, they have to consider the observing and measuring level as expected outcomes at visible or invisible levels, and the executing level as the response speed to types and amounts of changes. This consideration helps to create clarity in the strategic vision, mission, expectations, and performance in M\&A situations.

\section{Delimitation of Quantum-Culture Model}

The purpose of this proposed framework is to reflect on the feasibility of social behaviors and relationships compared to what nature bestows on us; it is not to solve the problems related to organizational culture directly. The discovery process for fit behaviors provides crucial clues to help organizations understand their contexts more deeply and to be able to create and maintain good organizational relationships.

\section{RECOMMENDATIONS FOR FUTURE RESEARCH}

Two recommendations are proposed. First, action/activity-based research is highly recommended. Essentially, conversations represent an important source of data that are fundamental in human actions. Observing real-time conversations is a vital process for understanding a group's social, cultural, and institutional practices. Further, the discussion of individual subjectivity, such as feelings and emotions, in both work and non-work settings helps to gain insight data (Elsbach \& Kramer, 2016), especially in complex M\&A settings.

Second, applying the theory-building process to this model development contributes to the heightened comprehensiveness of HRD theory. HRD scholars have suggested that theory-testing research is more applicable than theory-building with a philosophical framework of ontology, epistemology, and axiology. Additionally, they encourage the use of the normal research cycle, not shortcut cycles (Ruona \& Lynham, 2004).

\section{CONCLUSION}

Increasing research using a cross-cultural perspective encourages the continuous improvement and generates higher quality of international human resource development (HRD) (McLean, 2016). Focusing on the human interaction among subcultures in the main organizational culture is in line with the crosscultural perspective. It helps to generate a deeper understanding of multicultural inclusivity, diversity, and interpersonal communication. For this study, the cross-pollinated review of literature of scientific and social bodies of knowledge was used to generate the bridging view of quantum culture.

The purpose of this paper was to answer the research questions: (a) What is quantum-culture like as a model?; and (b) What are the characteristics of quantum-culture within the domain of M\&A? In order to answer the first research question, the quantum-culture model was presented as a means to providing a better explanation of M\&A complexity. This model depicts a causal relationship in the organization with a reflection of "atoms-to-molecule-to-matter" in accordance with "subcultures-to-main culture-toorganization". In order to answer the second research question, the characteristics of quantum-culture

depicted as common behavioral interaction was decoded by studying and metaphorically comparing the chemical reaction of a water molecule: (a) energy as organizational resources entitled to freeing, sharing, 
cohering, and exchanging behaviors; (b) bonding distance as contract with acknowledgment and respect to mutual and privacy space among members of the organization; and (c) orbital shape as organizational structure that needs observing, measuring level, and executing level to achieve a new vision or business model of the organization.

This model could provide a way to observe natural behaviors in human relationships and group interaction spontaneously and separately. Thus, a deeper understanding of highly-dynamic changes such as mergers and integration, can be achieved.

"Look Deep Into Nature and Then You Will Understand Everything Better" - Albert Einstein (Australian Association for Environmental Education, 2010, p. 91).

\section{REFERENCES}

Abascal, J. L., \& Vega, C. (2005). A general purpose model for the condensed phases of water: TIP4P/2005. The Journal of chemical physics, 123(23), 234505.

Abraham, M. R., Grzybowski, E. B., Renner, J. W., \& Marek, E. A. (1992). Understandings and misunderstandings of eighth graders of five chemistry concepts found in textbooks. Journal of research in science teaching, 29(2), 105-120.

Ancona, D. G., Goodman, P. S., Lawrence, B. S., \& Tushman, M. L. (2001). Time: A new research lens. Academy of management Review, 26(4), 645-663.

Ashish. (2015, July). Why don't we just make water chemically in a lab? Retrieved on November 20, 2017 from https://www.scienceabc.com/pure-sciences/why-dont-we-just-make-water-chemicallyin-a-lab-hydrogen-oxygen.html

Australian Association for Environmental Education (AAEE). (2010). Leading change: Living for one planet. 16th Biennial Australian Association for Environmental Education Conference, AAEE National Conference Committee.

Bertalanffy, L. V. (1972). The history and status of general systems theory. Academy of Management Journal, 15(4), 407-426.

Bohm, D. (1952). A suggested interpretation of the quantum theory in terms of "hidden" variables. Physical Review, 85(2), 166-179.

Bohm, D. (1990). A new theory of the relationship of mind and matter. Philosophical psychology, 3(2), 271-286.

Bohm, D. (2005). Wholeness and the implicate order. Routledge.

Boothe, B. A. (1989). Are we taking ourselves too seriously? In D. B. Gradous (Ed.), Systems theory applied to human resource development: Fourth in the theory-to-practice monograph series (pp. 20-26). University of Minnesota Training and Development Research Center, Department of Vocational and Technical Education and the American Society for Training and Development Research Committee.

Cheuk, B. (2007). Social networking analysis: Its application to facilitate knowledge transfer. Business Information Review, 24(3), 170-176.

Coelli, T., \& Fleming, E. (2004). Diversification economies and specialisation efficiencies in a mixed food and coffee smallholder farming system in Papua New Guinea. Agricultural Economics, 31(2-3), 229-239. doi:org/10.1016/j.agecon.2004.09.010

Cook, D. B. (2008). Quantum chemistry: A unified approach. London: Imperial College Press.

Cummings, T. G., \& Worley, C. G. (2005). Organization development and change. (8th ed.). Pre-Press. doi:10.1002/9780470753408.ch2

Deloitte, (2016). The new organization: Different by design. Global human capital trends. Deloitte University Press.

Deloitte, (2017). Rewriting the rules for the digital age. Global human capital trends. Deloitte University Press.

Eisner, E. W. (1997). The new frontier in qualitative research methodology. Qualitative inquiry, 3(3), 259-273. 
Elsbach, K. D., \& Kramer, R. K. (Eds.). (2016). Handbook of qualitative organizational research: Innovative pathways and methods. New York, NY: Routledge.

Fris, J., \& Lazaridou, A. (2006). An additional way of thinking about organizational life and leadership: The quantum perspective. Canadian Journal of Educational Administration and Policy, (48), 129.

Gaertner, S. L., Bachman, B. A., Dovidio, J., \& Banker, B. S. (2001). Corporate mergers and stepfamily marriages: Identity, harmony, and commitment. Social identity processes in organizational contexts, 265-282.

Gallopin, G. C., Funtowicz, S., O'Connor, M., \& Ravetz, J. (2001). Science for the twenty-first century: From social contract to the scientific core. International Social Science Journal, 53(168), 219229.

Gradous, D. (1989). Systems theory applied to human resource development: Fourth in the theory-topractice monograph series. University of Minnesota Training and Development Research Center, Department of Vocational and Technical Education and the American Society for Training and Development Research Committee.

Granger, J. (2017). The chemistry of water. Retrieved on September 12, 2017 from $\mathrm{http} / / /$ witcombe.sbc.edu/water/chemistryelectrolysis.html

Helmenstine, A. M. (2018, March). How to make water from hydrogen and oxygen. Retrieved on April 2, 2018 from https://www.thoughtco.com/making-water-from-hydrogen-and-oxygen-4021101

Hogg, M. A., \& Terry, D. J. (2001). Social identity process in organizational contexts. Psychology Press.

Horn, H. W., Swope, W. C., Pitera, J. W., Madura, J. D., Dick, T. J., Hura, G. L., \& Head-Gordon, T. (2004). Development of an improved four-site water model for biomolecular simulations: TIP4PEw. The Journal of chemical physics, 120(20), 9665-9678.

Humphrey, M., Pancella, P., \& Berrah, N. (2015). Quantum physics. New York, NY: Penguin Random House LLC.

KPMG, (2013). Future state 2030: The global megatrends shaping governments. KPMG International Cooperative.

Kroon, D. (2017). How do communication and cultural differences explain post-merger identification? Evidence from two merged daily firms. In S. Y. Tarba, C. L. Cooper, R. M. Sarala, \& M. F. Ahammad (Eds.), Mergers and acquisitions in practice (pp. 162-181). New York, NY: Routledge.

Lupina-Wegener, A., \& Dick, R. V. (2017). Multiple shared identities in cross-border M\&As. In S. Y. Tarba, C. L. Cooper, R. M. Sarala, \& M. F. Ahammad (Eds.), Mergers and acquisitions in practice (pp. 182-198). New York, NY: Routledge.

Lynham, S. A. (2000). Theory building in the human resource development profession. Human Resource Development Quarterly, 11(2), 159-178.

Ma, S. (2016, May). Physical and chemical properties of matter, LibreTexts libraries. Retrieved from https://chem.libretexts.org/Core/Inorganic_Chemistry/Chemical_Reactions/Properties_of_Matter

Maas, U., \& Warnatz, J. (1988). Ignition processes in hydrogen-oxygen mixtures. Combustion and Flame, 74(1), 53-69.

MacDougall, W. (2014). Industrie 4.0: Smart manufacturing for the future. Germany Trade \& Invest.

May, C., \& May, J. (2014). Are you VUCA ready? Lexington, KY: CreateSpace Independent.

Mazzocchi, F. (2008). Complexity in biology: Exceeding the limits of reductionism and determinism using complexity theory. EMBO reports, 9(1), 10-14.

McIntyre, D. H. (2012). Quantum mechanics: A paradigms approach. San Francisco, CA: Pearson Education.

McLagan, P. A. (1989). Systems model 2000: Matching systems theory to future HRD issues. In D. B. Gradous (Ed.), Systems theory applied to human resource development: Fourth in the theory-topractice monograph series (pp. 61-82). University of Minnesota Training and Development Research Center, Department of Vocational and Technical Education and the American Society for Training and Development Research Committee. 
McLean, G. N. (2016). Continuous improvement in international or global HRD research. Human Resource Development International, 1-7. doi:10.1080/13678868.2016.1188585

McMahon, P. E., Khomtchouk, B. B., \& Wahlestedt, C. (2017). Survival guide to organic chemistry: Bridging the gap from general chemistry. (1st ed.). New York, NY: CRC Press.

Phaopat, N., \& Mak, C. W. (2017, July). Human interaction of the organization and the organization of human interaction: A 7R view. In E. Tomé (Chair), The International Conference on Theory and Applications in the Knowledge Economy 2017 Proceeding. Symposium conducted at the meeting of Faculty of Economics and Business, University of Zagreb, Zagreb, Croatia.

Rieger, E. H. (1989). High-performance systems process: A new paradigm. In D. B. Gradous (Ed.), Systems theory applied to human resource development: Fourth in the theory-to-practice monograph series (pp. 144-155). University of Minnesota Training and Development Research Center, Department of Vocational and Technical Education and the American Society for Training and Development Research Committee.

Ruona, W. E., \& Lynham, S. A. (2004). A philosophical framework for thought and practice in human resource development. Human Resource Development International, 7(2), 151-164.

Schein, E. H. (2010). Organizational culture and leadership. (4th ed.). San Francisco, CA: John Wiley \& Sons.

Schmidt, J. A. (Ed.). (2002). Making mergers work: The strategic importance of people. Virginia, VA: SHRM Foundation.

Shiklomanov, I. A. (1998). World water resources: A new appraisal and assessment for the 21st century. UNESCO.

Skitka, L. J., \& Sargis, E. G. (2005). Social psychological research and the Internet: the promise and peril of a new methodological frontier. The social net: The social psychology of the Internet, 1-26.

Swanson, R. A. (2001). Human resource development and its underlying theory. Human Resource Development International, 4(3), 299-312.

United Nations. (2016). World economic situation and prospects 2016. NY: United Nations.

WWAP (World Water Assessment Programme). (2006). The United Nations world water development report 2-water: A shared responsibility. Paris: UNESCO.

WWAP (United Nations World Water Assessment Programme). (2018). The United Nations world water development report 2018: Nature-based solutions for water. Paris: UNESCO.

Wheatley, M. J. (2006). Leadership and the new science: Discovering order in a chaotic world. San Francisco, CA: Berrett-Koehler Publishers.

Zohar, D. (1990). The quantum self: Human nature and consciousness defined by the new physics. New York, NY: William Morrow.

Zohar, D., \& Marshall, I. (1994). The quantum society: Mind, physics, and a new vision. New York, NY: William Morrow. 